\title{
Alveolar bone healing process in spontaneously hypertensive rats (SHR). A radiographic densitometry study
}

\author{
Natalia MANRIQUE', Cassiano Costa Silva PEREIRA², Lourdes Maria Gonzáles GARCIA ${ }^{3}$, Samuel MICARONI ${ }^{3}$, \\ Antonio Augusto Ferreira de CARVALHO ${ }^{4}$, Sílvia Helena Venturoli PERRI ${ }^{5}$, Roberta OKAMOTO ${ }^{6}$, Doris Hissako \\ SUMIDA ${ }^{7}$, Cristina ANTONIALI ${ }^{8}$
}

\begin{abstract}
1- DDS, MSc, Graduate student, Department of Pediatric and Community Dentistry, School of Dentistry of Araçatuba, UNESP-Univ. Estadual Paulista, Araçatuba, SP, Brazil.

2- DDS, MSc, Post-graduate student, Department of Surgery and Integrated Clinic, School of Dentistry of Araçatuba, UNESP-Univ. Estadual Paulista, Araçatuba, SP, Brazil.

3- Undergraduate student, Department of Basic Sciences, School of Dentistry of Araçatuba, UNESP-Univ. Estadual Paulista, Araçatuba, SP, Brazil.

4- MSc, PhD, Assistant Professor, Department of Pathology and Clinical Propedeutics, School of Dentistry of Araçatuba, UNESP-Univ. Estadual Paulista, Araçatuba, SP, Brazil.

5- MSc, PhD, Assistant Professor, Department of Clinics, Surgery and Animal Reproduction, School of Veterinary Medicine, UNESP-Univ. Estadual Paulista, Araçatuba, SP, Brazil.

6- DDs, MSc, PhD, Graduate Program in Dentistry, School of Dentistry of Araçatuba, UNESP-Univ. Estadual Paulista, Araçatuba, SP, Brazil.

7- DDS, MSc, PhD, Associate Professor, Department of Basic Sciences, School of Dentistry of Araçatuba, UNESP-Univ. Estadual Paulista, Araçatuba, SP, Brazil.

8- MSc, PhD, Assistant Professor, Department of Basic Sciences, School of Dentistry of Araçatuba, UNESP-Univ. Estadual Paulista, Araçatuba, SP, Brazil.
\end{abstract}

Corresponding address: Cristina Antoniali - Faculdade de Odontologia de Araçatuba - UNESP - Departamento de Ciências Básicas - Rua: José Bonifácio 1193 - 16015-050 - Araçatuba - SP - Brasil - Phone: +55-18-3636-2756/ Fax: +55-18-3636-2756

Received: June 22, 2010 - Modification: November 17, 2010 - Accepted: January 18, 2011

\section{ABSTRACT}

Hypertension is one of the most important public health problems worldwide. If undiagnosed or untreated, this pathology represents a systemic risk factor and offers unfavorable conditions for dental treatments, especially those requiring bone healing. Objectives: The purpose of this study was to demonstrate, by analysis of bone mineral density (BMD), that the alveolar bone healing process is altered in spontaneously hypertensive rats (SHRs). Material and Methods: Wistar rats and SHRs were submitted to extraction of the upper right incisor and were euthanized 7, 14, 21, 28 and 42 days after surgery. Right maxillae were collected, radiographed and analyzed using Digora software. BMD was expressed as minimum (min), middle (med) and maximum ( $\max$ ) in the medium (MT) and apical (AT) thirds of the dental alveolus. Results: The results were compared across days and groups. Wistar showed difference in med and max BMD in the MT between 7 and 28 and also between 14 and 28 days. The AT exhibited significant difference in med and min BMD between 7 and 28 days, as well as difference in min BMD between 28 and 42 days. SHRs showed lower med BMD in the MT at 28 days when compared to 21 and 42 days. Differences were observed across groups in med and min BMD at day 28 in the MT and AT; and in max BMD at 14, 21 and 42 days in the MT. Conclusions: These results suggest that the alveolar bone healing process is delayed in SHRs comparing with Wistar rats.

Key words: Tooth socket. Bone density. Hypertension. Spontaneously hypertensive rats.

\section{INTRODUCTION}

The high prevalence of hypertension in the population and its implications make this disease a public health problem worldwide. Approximately fifty to sixty percent of hypertensive patients are unaware of their condition and only ten percent of dentist surgeons keep records of patients' blood pressure. Undiagnosed or untreated hypertension impairs some dental procedures, mainly those related to bone healing.

Local or systemic factors may contribute 
to alterations in the bone healing process. Systemic hypertension causes a series of damaging physiological alterations, depending on its intensity and duration 26 ; for instance, alteration in the calcium metabolism inducing bone loss. It is also known that medication taken by hypertensive patients may interfere in the alveolar bone healing process. Some authors demonstrated that amlodipine, a calcium channel antagonist, reduces bone formation in the dental alveolus of rats $^{27}$. Therefore, previous hypertension diagnosis and treatment are fundamental to obtain better results in oral rehabilitation with implant-supported prostheses that require substantial bone healing ${ }^{21}$.

The bone healing process following dental extraction has been extensively studied by histological and radiographic methods in humans ${ }^{10,23,28}$ as well as in animals ${ }^{12,20}$. Radiography is the most commonly used method in clinical evaluation for being fast, non-invasive and inexpensive, permitting longitudinal analysis. The bone healing process is easily interpreted by a radiopacity increase, which can be measured by optical density analysis 5 .

Clinical protocols recommend that preventive maintenance visits be carried out every three months in hypertensive patients for a couple of years following osseointegrated implant placement, in order to reduce risks of long-term complications ${ }^{21}$. Early identification of defects during the osseointegration process may avoid or minimize peri-implant alveolar bone loss, increasing predictability and favoring treatment aesthetics ${ }^{18}$. According to Van Steenberghe, et al. ${ }^{29}$ (2002) high percentages of implant failures occur mainly in bone type IV, which presents discrete cortical component associated with trabecular bone exhibiting less mineralization and large medullary spaces. The specific characteristics of this bone type are similar to those found in bones of spontaneously hypertensive rats (SHRs) ${ }^{14,30}$. The SHR is the closest experimental animal model to human essential hypertension. These animals are born normotensive and develop an increase in the blood pressure from the eighth week-old, reaching values close to 200 $\mathrm{mmHg}$ at twelve weeks old ${ }^{25}$.

The purpose of this study was to demonstrate, by analysis of bone mineral density (BMD), that the alveolar bone healing process is altered in SHRs.

\section{MATERIAL AND METHODS}

\section{Animals}

All experiments were approved by the Animal Research Ethics Committee (CEEA) at the School of Dentistry of Araçatuba (process number 2008001397). Male SHRs and normotensive Wistar rats weighing between 180 and $230 \mathrm{~g}$ were used.
The animals were kept in an artificially controlled environment with temperature ranging from 22 to $24^{\circ} \mathrm{C}$, on a $12: 12 \mathrm{~h}$ light/dark cycle and were fed food and water ad libitum.

\section{Experimental groups}

Animals were divided into two experimental groups: 1) normotensive Wistar rats and 2) SHRs. Each group was evaluated at five different times: 7, 14, 21, 28 and 42 days following tooth extraction. For each reading time five animals were used.

\section{Blood pressure monitoring}

The systolic arterial blood pressure (SBP) monitoring was performed by indirect tail cuff plethysmography, using a plethysmography device adapted for measurement in rats. Wistar rats and SHRs with SBP close or similar to 112 $\mathrm{mmHg}$ and similar or above $150 \mathrm{mmHg}$ were used, respectively. The SBP was taken at preoperative and postoperative time periods ( $7,14,21,28,42$ days).

\section{Surgery}

Animals were anesthetized by administration of a solution of ketamine chloride $(50 \mathrm{mg} / \mathrm{kg}$ i.m., Dopalen ${ }^{\circledR}$, Vetbrands/10 mL, Jacareí, SP, Brazil) and xylazine chloride $\left(10 \mathrm{mg} / \mathrm{kg}\right.$, i.m., Coopazine ${ }^{\circledR}$, Coopers Brasil LTDA/10 mL, São Paulo, SP, Brazil). Antisepsis of the anterior portion of the maxilla was performed using iodized polyvinylpyrrolidone and extraction of the upper right incisor was done using specially adapted tools, according to the technique described by Okamoto and Russo 22 (1973). The tooth luxation was carried out using a Hollenbeck instrument adapted to insert its active end between the tooth and the medial cortical border where lateral movements were performed following tooth extraction using adapted clamp clinic. The margins of the surgical wounds were sutured with sterile

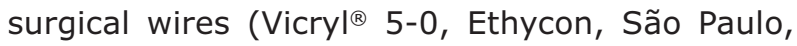
$\mathrm{SP}$, Brazil). After surgery each animal received a single $0.2 \mathrm{~mL}$ intramuscular dose of antibiotic $(1.7 \mathrm{~g} / 3 \mathrm{~mL}$ Veterinary Pentabiotic, Fort DODGE, Campinas, SP, Brazil). During two postoperative days, animals were fed ground rat chow to facilitate feeding (minimize both trauma at surgical site and healing process delay). After this period, standard lab block food was reintroduced.

\section{Sample collection}

Animals were euthanized at 7, 14, 21, 28 and 42 days after surgery in chamber saturated with halothane vapor. Next, the upper right maxilla was separated from the left part by means of median sagittal incision following the intermaxillary suture. Alveolar bone samples were obtained through tangential cuts to the molar distal faces using surgical scissors. Immediately after collection, the 
samples were immersed in $10 \%$ buffered formalin solution ( $\mathrm{pH} 7.0$ ) for $48 \mathrm{~h}$ for tissue structure preservation. All soft tissue around the samples as well as the zygomatic arch was removed to avoid possible interference in the radiography.

\section{Densitometric analysis of the dental alveolus}

Radiographs were taken $24 \mathrm{~h}$ after sample collection. To obtain radiographic images, an $X$ GE-100 (General Electric, WI, USA), operating at $50 \mathrm{kvp}, 10 \mathrm{~mA}, 0.166 \mathrm{~s}$ was used. The distance focus-film was $40 \mathrm{~cm}$, with perpendicular incidence to the film-object plane.

Direct digital image was obtained with optical plate from the digital system Digora (Soredex, Orion Corporation, Helsinki, Finland). Over each optical plate, one sample was placed and identified with lead letters and numbers. One image was obtained for each sample per animal of each experimental group at the different postoperative periods.

The sensitized optical plates were scanned and analyzed using Digora for Windows 1.51 software. This software provides, among other resources, the analysis of radiographic density (bone mineral density, BMD) by means of its gray levels.

Areas of specific sizes, visible in all digitalized images, were selected for densitometric analysis. In the middle third (MT), the area analyzed was $46 \times 18$ pi (pixels) and in the apical third (AT) $20 \times 20$ pi. Both size and anatomical shape (curve) of the socket, as well as limitations of the analysis program (Digora) determined the differences between the analysed areas in AT and MT, thus justifying the different measures (in pixels) used. Selected areas in both thirds comprised the largest possible area to be analysed in all sockets, without the involvement of cortical bone. One measurement in each area per image was done corresponding to the BMD of the area.

In the alveolar bone healing process, newly formed bone has different levels of mineralization, related to the formation of bone trabeculae. So these differences in mineralization levels resulted in BMD radiographic differences described as minimum ( $\min )$, maximum ( $\max$ ) and medium densities, which were expressed as gray level values. Max BMD values show the amount of mineralized tissue in the selected area, the values of min BMD are related to the amount of non-mineralized tissue in the area and medium BMD values are related to differences between the gray scales found in this specific area.

\section{Statistical analysis}

The data were expressed as means and standard error of the mean (SEM); and analyzed by two-way ANOVA and Tukey's post-hoc test. Significance level among postoperative days and between groups was set at $p<0.05$.

\section{RESULTS}

\section{Systolic Blood Pressure (SBP)}

The SBP was taken before surgery and at 7, $14,21,28$ and 42 days after surgery. The SBP of SHRs was higher $(p<0.05)$ than of Wistar rats in all analyzed periods (Figure 1 ).

BMD analysis of the alveolar bone healing

In the MT of the dental alveolus of Wistar rats, med and max BMD values observed on day 28 were higher than values from days 7 and 14 postoperatively; while min BMD values showed no significant difference (Figure 2). The AT of the dental alveolus exhibited higher med and min BMD on day 28 when compared with day 7 , as well as significant reduction in $\min$ BMD on day 42 when compared with day 28 (Figure 3).

SHRs exhibited lower BMD (med and $\min$ ) in the MT of the alveolus on day 28 when compared with day 21 post surgery (Figure 2 ). On the other hand, a higher DMB ( $m e d$ ) was noted at 42 days when compared with 28 days; while no difference in max BMD values was noted. The AT exhibited no significant alteration (Figure 3 ).

Intergroup comparison revealed lower BMD (med and $\mathrm{min}$ ) at 28 days in both thirds of the alveolus of SHRs (Figure 2). Max BMD values were higher in the MT of the alveolus of SHRs at 14, 21 and 42 days. However, max BMD values did not alter med BMD measurements, since med BMD values of the periods mentioned in SHRs were not significantly different from those observed in Wistar rats.

\section{DISCUSSION}

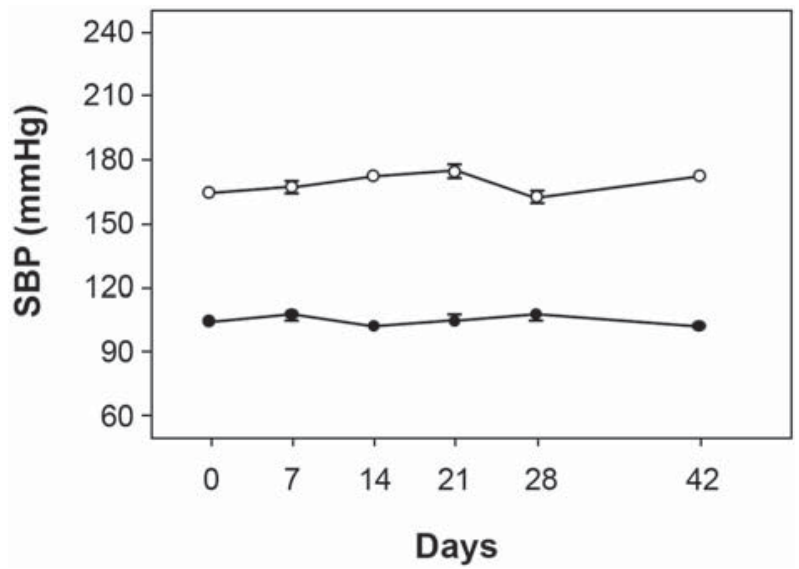

Figure 1- Systolic arterial blood pressure (SBP) of Wistar rats (closed circles, $n=5$ ) and spontaneously hypertensive rats (SHRs) (open circles, $n=5$ ). Symbols represent means $\pm S E M$ of the experiments performed 


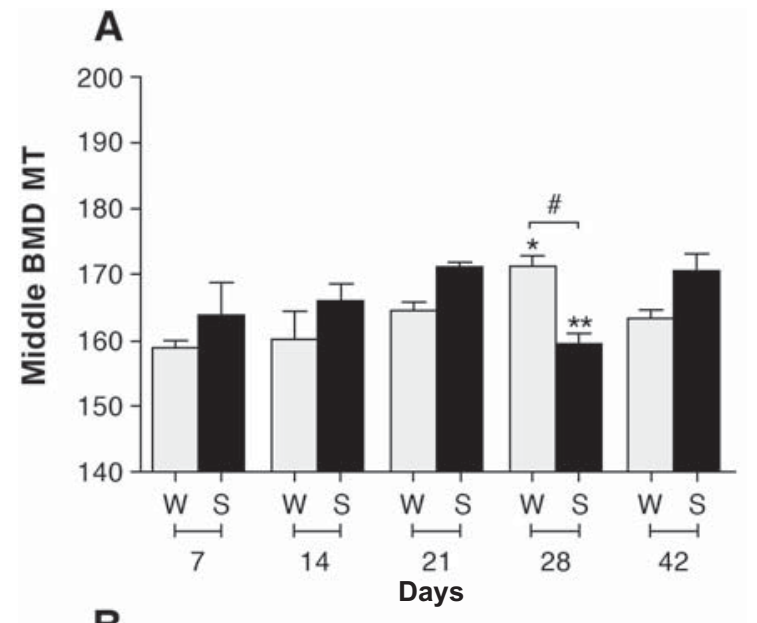

B
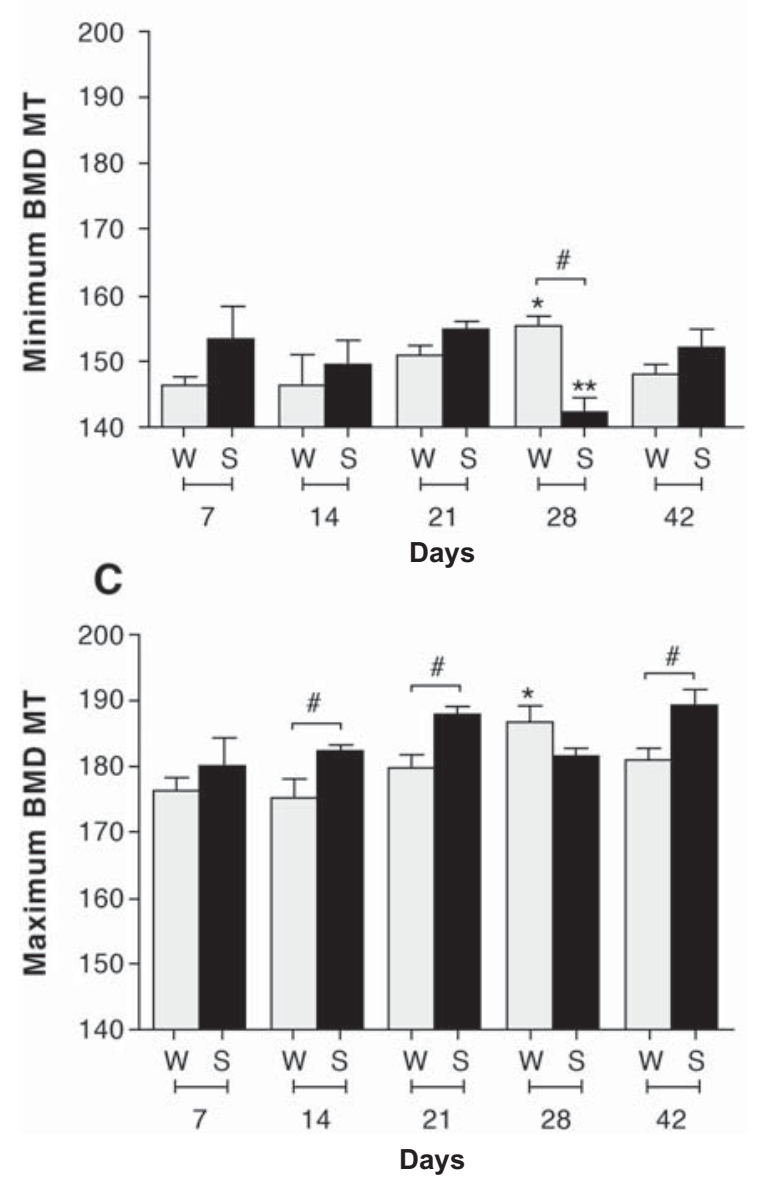

Figure 2- Bone mineral density (BMD) in the middle third (MT) of the alveolus. A) Middle BMD, B) Minimum BMD, C) Maximum BMD. *Difference among postoperative days of Wistar rats (Medium and maximum BMD: 28x7, $28 \times 14$ days). ${ }^{* *}$ Difference among postoperative days of spontaneously hypertensive rats (SHRs) (medium BMD: 28x21, 28x42 days; minimum BMD: $28 \times 21$ days). \#Difference between groups. W: Wistar S: SHR $(p<0.05$, ANOVA)

To the best of our knowledge, the present study demonstrated for the first time that the alveolar dental healing process is altered in SHRs, when
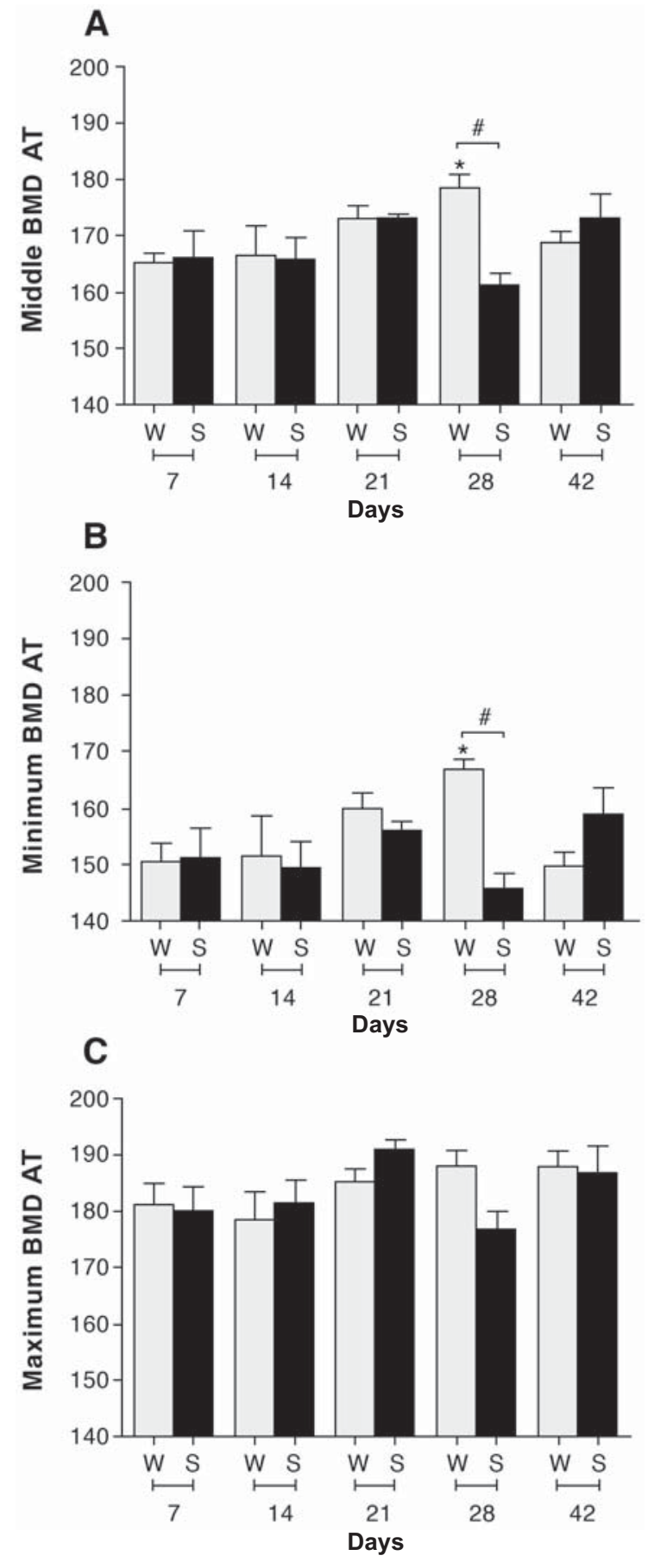

Figure 3- Bone mineral density (BMD) in the apical third (AT) of the alveolus. A) Middle BMD, B) Minimum BMD, C) Maximum BMD. *Difference among postoperative days of Wistar rats (Medium and minimum BMD: 28x7 days). \#Difference between groups. W: Wistar. S: spontaneously hypertensive rats $(\mathrm{SHR})(\mathrm{p}<0.05$, ANOVA)

compared with normotensive Wistar rats. The results suggest that hypertension delays alveolar bone healing.

It has been widely accepted that the most appropriate control strain to SHR studies is the Wistar-Kyoto (WKY) rat, to which SHRs are genetically related. Concerns have been raised 
about genetic differences ${ }^{9}$ and biological variability ${ }^{16}$ between SHRs and WKY rats. Moreover, evidence suggests that the WKY strain is not the most suitable for backcross studies due to incidence of spontaneous hypertension and somewhat higher levels of blood pressure in these rats ${ }^{1,2,19,24}$. According to several studies ${ }^{3,11,15,17}$, SHRs were compared to Wistar rats, which are safely normotensive and have no genetic alteration that could modulate arterial pressure.

Densitometric analysis showed that an expected gradual BMD increase was not observed in relation to the sequence of postoperative days in normotensive rats; however, a higher BMD at 28 days was observed in the MT and AT of the dental alveolus. These results suggest that there is significant bone formation at 28 days of the healing process. Guglielmotti and Cabrini ${ }^{13}$ (1985) also analyzed alveolar bone healing in Wistar rats, based on histometric parameters including volume density of bone; however, in a restricted area of the apical third. Although no statistical analysis was performed in that study ${ }^{13}$, high radiographic density was observed all over the healing extension, leaving the alveolus walls undistinguishable around day 30 post surgery.

The present data can be corroborated by histometric studies that observed no difference in the quantity of bone tissue formed in the dental alveolus of Wistar rats one, two and three weeks after surgery ${ }^{31}$ and continuous osseous neoformation was also observed over 21 days after surgery $^{8}$. In the present study, lower min BMD was observed at 42 days in relation to 28 days in the AT of the alveolus of Wistar rats, with no alteration of max BMD values. These data suggest that the reduction of medullary spaces between the trabeculae can be associated with the formation of a more compact bone tissue, as demonstrated in a previous histological study that evaluated the alveolar healing process at 42 days after tooth extraction in Wistar rats ${ }^{8}$. Cardaropoli, et al. ${ }^{6}$ (2003) also observed that at 30 days of healing, most parts of the extraction socket were filled with newly formed bone that was continuous with bone of the socket walls; moreover, in some areas they noted that the woven bone was undergoing osteoclastic resorption, indicating that the process of modeling/ remodeling of newly formed bone had begun.

In the alveolus of SHRs, the reduction in med and $\min$ BMD in the dental alveolus at 28 days in relation to 21 days, with subsequent increase at 42 days, demonstrated that the healing process did not follow the same pattern observed in Wistar rats. The lower med BMD at 28 days in SHRs revealed a reduced quantity of bone tissue or a less mineralized bone tissue. Alveolar healing process alteration, characterized by immature bone tissue, was also noted between 9 and 21 days after upper incisor tooth extraction using a renal hypertensive (Goldblatt rats 1-kidney, 1-clip) animal model7. Bastos, et al. ${ }^{3}$ (2010) observed in the tibia of SHR that the mean percentage of trabecular bone area formed after critical-size defect was significantly lower when compared to normotensive rats. Our results concerning alveolar bone healing are in agreement with previous studies that showed alveolar bone disorders in SHRs during ligatureinduced periodontal disease, when compared to normotensive Wistar rats. It was demonstrated an exacerbated response to periodontal disease ${ }^{17}$ with an increased bone resorption and decreased bone density in SHRs ${ }^{4}$.

\section{CONCLUSION}

The findings of the present study demonstrate that BMD in the dental alveolus of spontaneously hypertensive rats is significantly decreased at 28 days after tooth extraction, strongly suggesting a delay of the alveolar healing process under this pathological condition. Further investigations should be carried out in order to determine the mechanisms involved in the alveolar healing process in this spontaneously hypertensive animal model.

\section{ACKNOWLEDGEMENTS}

The authors would like to thank The State of São Paulo Research Foundation - FAPESP (Process number 2008/01893-0) and also CAPES and UNESP Research Internationalization Program (PROINTER/ PROPe - UNESP) for the financial support.

\section{REFERENCES}

1- Alexander D, Gardner JP, Tomonari H, Fine BP, Aviv A. Lower $\mathrm{Na}(+)-\mathrm{H}+$ antiport activity in vascular smooth muscle cells of Wistar-Kyoto rats than spontaneously hypertensive and Wistar rats. J Hypertens. 1990;8:867-71.

2- Ashida T, Kuramochi M, Omae T. Increased sodium-calcium exchange in arterial smooth muscle of spontaneously hypertensive rats. Hypertension. 1989;13:890-5.

3- Bastos MF, Brilhante FV, Bezerra JP, Silva CA, Duarte PM. Trabecular bone area and bone healing in spontaneously hypertensive rats: a histometric study. Braz Oral Res. 2010;24:1706.

4- Bastos MF, Brilhante FV, Gonçalves TE, Pires AG, Namipoga $\mathrm{MH}$, Marques MR, et al. Hypertension may affect tooth-supporting alveolar bone quality: a study in rats. J Periodontol. 2010;81:107583.

5- Bodner L, Kaffe I, Littner MM, Cohen J. Extraction site healing in rats. A radiologic densitometric study. Oral Surg Oral Med Oral Pathol. 1993;75:367-72.

6- Cardaropoli G, Araújo M, Lindhe J. Dynamics of bone tissue formation in tooth extraction sites. An experimental study in dogs. J Clin Periodontol. 2003;30:809-18. 
7- Carvalho AA, Castro AL, Melhado RM, Castro JCB. Healing of tooth extraction wounds in rats with renal hypertension. A histological study. J Nihon Univ Sch Dent. 1983;25:214-20.

8- Carvalho TL, Bombonato KF, Brentegani LG. Histometric analysis of rat alveolar wound healing. Braz Dent J. 1997;8:9-12.

9- Charchar FJ, Kaiser M, Bingham AJ, Fotinatos N, Ahmady F, Tomaszewski $M$, et al. Whole genome survey of copy number variation in the spontaneously hypertensive rat: relationship to quantitative trait loci, gene expression, and blood pressure. Hypertension. 2010;55:1231-8.

10- Crespi R, Capparè P, Gherlone E. Magnesium-enriched hydroxyapatite compared to calcium sulfate in the healing of human extraction sockets: radiographic and histomorphometric evaluation at 3 months. J Periodontol. 2009;80:210-8

11- Elias GP, Sassaki KT, Delbem AC, Antoniali C. Atenolol reduces salivary activity in pups of spontaneously hypertensive and normotensive rats treated during pregnancy and lactation. Clin Exp Hypertens. 2008;30:133-41.

12- Gorustovich AA, Steimetz T, Nielsen FH, Guglielmotti MB. Histomorphometric study of alveolar bone healing in rats fed a boron-deficient diet. Anat Rec (Hoboken). 2008;291:441-7.

13- Guglielmotti MB, Cabrini RL. Alveolar wound healing and ridge remodeling after tooth extraction in the rat: a histologic, radiographic and histometric study. J Oral Maxillofac Surg. 1985;43:359-64.

14- Izawa Y, Sagara K, Kadota T, Makita T. Bone disorders in spontaneously hypertensive rat. Calcif Tissue Int. 1985;37:605-7. 15- Kristek F, Koprdová R, Cebová M. Long-term effects of early administered sildenafil and NO donor on the cardiovascular system of SHR. J Physiol Pharmacol. 2007;58:33-43.

16- Kurtz TW, Morris RC Jr. Biological variability in Wistar-Kyoto rats. Implications for research with the spontaneously hypertensive rat. Hypertension. 1987;10:127-31.

17- Leite CL, Redins CA, Vasquez EC, Meyrelles SS. Experimentalinduced periodontitis is exacerbated in spontaneously hypertensive rats. Clin Exp Hypertens. 2005;6:523-31.

18- Levin L. Dealing with dental implant failures. J Appl Oral Sci. $2008 ; 16: 171-5$

19- Louis WJ, Howes LG. Genealogy of the spontaneously hypertensive rat and Wistar-Kyoto rat strains: implications for studies of inherited hypertension. J Cardiovasc Pharmacol. 1990:16:S1-5.
20- Mendes RM, Silva GA, Lima MF, Calliari MV, Almeida AP, Alves $\mathrm{JB}$, et al. Sodium hyaluronate accelerates the healing process in tooth sockets of rats. Arch Oral Biol. 2008;53:1155-62.

21- Misch CE. Medical evaluation of the implant patient. In: Misch CE. Contemporary implant dentistry. St. Louis: Mosby; 1999. p. 33-65.

22- Okamoto T, Russo MC. Wound healing following tooth extraction. Histochemical study in rats. Rev Fac Odontol Araçatuba. 1973;2:153-69.

23- Saldanha JB, Casati MZ, Neto FH, Sallum EA, Nociti $\mathrm{FH}$ Jr. Smoking may affect the alveolar process dimensions and radiographic bone density in maxillary extraction sites: a prospective study in humans. J Oral Maxillofac Surg. 2006;64:1359-65.

24- Sato T, Arai M, Goto S, Togari A. Effects of propranolol on bone metabolism in spontaneously hypertensive rats. J Pharmacol Exp Ther. 2010;334:99-105.

25- Sugiyama T, Yoshizumi M, Takaku F, Urabe H, Tsukakoshi M, Kasuya $T$, et al. The elevation of the cytoplasmic calcium ions in vascular smooth muscle cells in SHR - measurement of the free calcium ions in single living cells by lasermicrofluorospectrometry. Biochem Biophys Res Commun. 1986;141:340-5.

26- Tarazi RC, Gifford RW Jr. Left ventricular hypertrophy and hypertension. JAMA. 1983;250:1319.

27- Teófilo JM, Brentegani LG, Carvalho TL. A histometric study in rats of the effect of the calcium antagonist amlodipine on bone healing after tooth extraction. Arch Oral Biol. 2001;46:375-9.

28- Van der Weijden F, Dell'Acqua F, Slot DE. Alveolar bone dimensional changes of post-extraction sockets in humans: a systematic review. J Clin Periodontol. 2009;36:1048-58.

29- Van Steenberghe D, Jacobs R, Desnyder M, Maffei G, Quirynen $M$. The relative impact of local and endogenous patient-related factors on implant failure up to the abutment stage. Clin Oral Implants Res. 2002;13:617-22.

30- Wang TM, Hsu JF, Jee WS, Matthews JL. Evidence for reduced cancellous bone mass in the spontaneously hypertensive rat. Bone Miner. 1993;20:251-64.

31- Yugoshi LI, Sala MA, Brentegani LG, Carvalho TLL. Histometric study of socket healing after tooth extraction in rats treated with diclofenac. Braz Dent J. 2002;13:92-6. 